\title{
Intervenção do Estado e (re)estruturação urbana. Um estudo sobre gentrificação
}

\author{
State intervention and urban (re)structuring. \\ A study on gentrification
}

Carlos Ribeiro Furtado

\section{Resumo}

De acordo com este artigo, gentrificação é consequência de mudanças, não apenas na qualidade, composição e distribuição da força de trabalho, mas principalmente, e primeiramente, na reorganização do espaço para produção, circulação e consumo de mercadorias. Isso coloca a compreensão do conceito como parte de um amplo e complexo processo de (re)estruturação urbana ligando o conceito também a processos específicos de (re)organização espacial, expandindo assim seu significado de forma a dar conta de alguns processos de gentrificação que, de outra forma, ficariam obscurecidos. Para tanto apresentamos o estudo de caso de "Dona Teodora" em Porto Alegre, onde o Estado aparece não só como o principal condutor dos processos de reestruturação urbana que aí ocorrem, mas, também, como o agente do processo de gentrificação.

Palavras-chave: gentrificação; renovação urbana; segregação social; (re)estruturação urbana; desenvolvimento desigual.

\begin{abstract}
According to this paper, gentrification is a consequence of changes not only in the quality, composition and distribution of labor force, but first and foremost in space reorganization for commodity production, circulation and consumption. According to this view, the concept should be understood as part of a wide and complex process of urban (re)structuring; in addition, it links the concept to specific processes of spatial (re)organization, thus widening its meaning so as to enable it to explain some gentrification processes that would otherwise remain unknown. To illustrate our proposition, we present the case study of "Dona Teodora", in the city of Porto Alegre, where the State is not only the main conductor of the urban restructuring processes, but also the agent of the gentrification process.
\end{abstract}

Keywords: gentrification; urban renewal; social segregation; urban (re)structuring; unequal development. 


\section{Entendendo o processo de gentrificação na nova ordem urbana}

Se olharmos para trás, para as descrições de alguns processos de remoção de trabalhadores, percebemos que o processo de gentrificação ${ }^{1}$ parece não um novo, mas, antes, a nova forma de um velho processo:

A melhoria das cidades, acompanhando o crescimento da riqueza, através da demolição de quarteirões mal construídos, a construção de palácios para bancos, grandes depósitos, etc., o alargamento de ruas para o tráfego comercial, para luxuosas carruagens e para a introdução dos bondes, etc., erradicam os pobres para lugares escondidos ainda piores e mais densamente ocupados. (Marx, 1967, v. 1, p. 657)

Essa citação de Marx, escrita há mais de 100 anos, nos parece a descrição de um processo de gentrificação muito mais apropriada do que a de Glass e muito similar a seu entendimento mais recente.

Se a reestruturação que iniciou agora continua na sua atual direção, nós podemos esperar por importantes mudanças na estrutura urbana [...]. A conclusão lógica da reestruturação atual [...] seria a de um centro urbano dominado pelos profissionais-executivos, pelas funções financeiras e administrativas, residências das classes média e média alta e mais os serviços necessários a estas classes tais como hotéis, restaurantes, comércio, cinema e cultura [...]. 0 corolário disto seria um desalojamento substancial da classe trabalhadora para os velhos subúrbios e a periferia urbana. (Smith, 1986, p. 32)
Assim, o processo de gentrificação aparece como um dos elementos de um processo permanente de (re)estruturação urbana. Processo esse que é parte da organização do espaço urbano, de acordo com as necessidades do modo de produção dominante na economia e que está em sintonia com os propósitos da estrutura dominante da sociedade em um período histórico determinado. Como explica Smith:

A expansão econômica se desenvolve hoje não através da expansão geográfica absoluta, mas através da diferenciação interna do espaço geográfico. A produção do espaço, ou desenvolvimento geográfico hoje é, no entanto, um processo absolutamente desigual. Gentrificação, renovação urbana e os maiores e mais complexos processos de reestruturação urbana são todos parte da diferenciação do espaço geográfico na escala urbana. (Ibid, p. 18)

Dessa forma, é difícil isolar gentrificação como um simples caso de substituição de habitação de baixo custo por projetos habitacionais para as camadas média e alta. Segundo Smith e Williams (1986), o que está em jogo hoje em dia é um processo de gentrificação da cidade. ${ }^{2}$

Isso não significa que exista um padrão universal, que esteja, de agora em diante, sendo reproduzido continuamente, mas somente que esse é o padrão do momento presente. É também importante dizer que ele não determina uma tendência irreversível, de exclusão de toda a classe trabalhadora da área urbana central da cidade nas sociedades capitalistas. Alguns enclaves podem e devem ocorrer com habitação de baixo custo, ou mesmo irregulares, permanecendo nas áreas ocupadas pelas 
camadas média e alta na medida em que elas são funcionais para essas camadas sociais.

Grande parte da bibliografia procura evidenciar, tanto do ponto de vista dos estudos empíricos quanto dos debates teóricos, que há uma concepção generalizada do processo de gentrificação como uma forma de revitalização ou renascimento urbano. Essa perspectiva implica aceitar um certo tipo de decadência secular anterior e, agora, uma reversão dos caminhos até então estabelecidos nas cidades.

Essa é, de fato, a história dos programas de revitalização dos centros da maioria das cidades americanas e europeias de hoje ou, pelo menos, e apenas, a faceta mais divulgada dos processos mais recentes de gentrificação; uma história verdadeira, mas parcial.

A história do desenvolvimento urbano é uma história de constantes padronizações e transformações da cidade, que se torna mais rápida e institucionalizada com o advento do capitalismo. Esse processo de transformação necessita ser visto como uma constante (re) estruturação do espaço urbano, com nada permanecendo intocado por muito tempo. Como diz Harvey:

A corrida do ser humano através do espaço é agora marcada por uma aceleração do passo das mudanças no ambiente urbano construído, através do qual eles correm. Processos tão diversos como suburbanização, desindustrialização e reestruturação, gentrificação e renovação urbana, em direção a uma total reorganização da estrutura espacial da hierarquia urbana, são parte de um processo geral de contínua reformulação de ambientes geográficos para atender as necessidades de aceleração do tempo no espaço. (1985a, p. 28)
No entanto, é preciso sublinhar que, mesmo tomando o processo de gentrificação como um evento específico das sociedades capitalistas, não se deve esquecer que os processos envolvidos são sempre particulares, tanto com relação a diferentes períodos no tempo em uma mesma sociedade, quanto, e muito especialmente, com relação a formações sociais distintas.

Assim, o fenômeno de gentrificação precisa ser explicado tanto por tendências estruturais, quanto por especificidades históricas, sem retirá-lo, contudo, do ponto de vista teórico, do contexto social do qual ele é parte. Mais precisamente, o processo de gentrificação necessita ser teorizado como parte da totalidade orgânica da formação social, o que significa procurar as causas do processo de gentrificação na conjuntura da produção, circulação e consumo.

\section{Reformulando o problema}

Bourdieu (1996) postula a necessidade de as ciências sociais assumirem uma postura reflexiva diante da aplicação de conceitos e pressuposições a outras realidades sociais, que não aquelas onde, e para onde, os mesmos foram criados e aplicados.

Para Bourdieu, somente conseguiremos construir um modelo de análise que possa ser aplicado a outras realidades sociais quando formos capazes de construir um conceito a partir da análise objetiva de uma realidade social.

Para que isso seja possível, devemos capturar a lógica mais profunda de um mundo social, submergindo na particularidade de sua realidade empírica, historicamente situada 
e datada, para construí-la, não como um modelo universal, mas, como diz Bourdieu, como uma figura em um universo de configurações possíveis. Somente dessa forma o pesquisador pode apreender os princípios de construção do espaço social e os mecanismos de reprodução desse espaço e, assim, representá-lo em um modelo com a pretensão de validade universal. Através da construção do espaço social, que organiza as práticas e as representações dos agentes, procurando e identificando as causas, o princípio e os elementos geradores de sua construção e transformação, o pesquisador pode indicar as diferenças reais que separam as estruturas e cujo princípio é preciso procurar nas particularidades de histórias coletivas diferentes (Bourdieu, 1996).

Assim, se queremos formular um conceito para explicar a diferenciação constitutiva do espaço social, é preciso, em primeiro lugar, romper com a propensão ao pensamento substancialista e ingenuamente realista que, ao invés de preocupar-se com relações, preocupa-se com realidades fenomênicas nas quais elas se manifestam (Bourdieu, 1996).

Sustentamos, portanto, que os exemplos de gentrificação atualmente apresentados em muitos países, como por exemplo: Estados Unidos, Inglaterra e Canadá, não podem ser tomados como modelos universais, mas como uma das possíveis facetas do processo ou, como dito anteriormente, como uma figura em um universo de configurações possíveis. Nesse sentido, nem os aspectos geográficos nem os atores envolvidos no processo devem ser, necessariamente, sempre os mesmos.

Reconhecendo, também, que a origem do padrão de segregação social que ocorre nas cidades de qualquer economia de hoje é consequência de transformações econômicas e sociais que aconteceram no passado, assumimos que os resultados derivados de transformações econômicas e sociais podem ser distintos se tomarmos espaço e tempo distintos. As mudanças na estrutura do mercado de trabalho, a crescente divisão social e os diferentes fatos e acontecimentos associados a elas (a crescente separação entre camadas sociais, a estrutura de preços e hierarquia de usos do solo urbano e a estrutura de distribuição de riqueza) levam-nos a explorar a possibilidade de encontrar padrões de desenvolvimento urbano distintos em diferentes formações sociais.

Entendemos que o processo de gentrificação é um visível componente espacial da transformação social. Como tal, tem se apresentado como um processo altamente dinâmico, que não aceita mais definições muito restritas. Assim, restringir o significado e a aplicação do conceito, impondo-lhe um padrão definitivo, é, hoje em dia, no mínimo um risco. Por isso, nós concordamos quando Smith diz que:

Nós deveríamos nos esforçar em considerar a grande quantidade de processos e agentes que contribuem para esta reestruturação, entender as relações entre processos aparentemente independentes e, desta forma, buscar e construir novos estudos de caso para assim redefinir 0 conceito. (1986, p. 3)

Ao analisar o processo de gentrificação em "Dona Teodora" ${ }^{3}$, percebemos que ele tem suas próprias peculiaridades bem distintas do processo de gentrificação, estudado por Ley (1981), que veio a transformar a área central de Vancouver. Para Ley esse processo foi determinado por uma nova ética do capital baseada em preferências (gosto e estética) ${ }^{4}$ de uma 
"nova classe média", pressionando os trabaIhadores de baixa qualificação para a periferia. Em nossa pesquisa em "Dona Teodora", verificamos algo distinto, onde o Estado e o setor terciário desempenharam um papel imprescindível no processo.

A produção do espaço em "Dona Teodora" é a expressão geográfica da utilização do solo urbano por atividades econômicas para a produção, circulação e consumo de mercadorias na forma de bens e serviços e mais habitação. Assim, o processo de gentrificação em "Dona Teodora" não pode ser visto como a expressão de uma mudança nas preferências de consumo por habitação entre alguns setores da classe média, mas, principalmente, como o resultado da necessidade de reorganização do espaço urbano para atender as necessidades dos setores de serviço, comércio atacadista e varejista, bem como de alguns setores da indústria de pequeno porte e alta tecnologia. No caso específico da habitação, como veremos, os investimentos em moradia para a classe média em "Dona Teodora" foram efetuados com sucesso somente a partir do início da década de 1990, após a consolidação da área como uma zona de comércio e serviços.

No processo de (re)organização do espaço em "Dona Teodora", a confrontação entre os diversos ocupantes aparece como uma força motora, com o Estado mediando o processo de fornecimento dos meios necessários para que o processo de gentrificação se desenvolvesse.

Nesse sentido, a análise desenvolvida por Hamnett e Williams (1979) traz importantes contribuições, especialmente no que se refere à discussão sobre a participação do Estado na mediação do processo de gentrificação, através do fornecimento de recursos físicos e financeiros que terminam por acelerar, pelo aumento do preço do solo, o processo de expulsão indireta, e também direta, dos trabalhadores.

0 capitalismo constrói um ambiente físico e social de acordo com sua própria imagem, apropriada à sua própria condição em um determinado momento no tempo. Mas esse ambiente é construído somente para ser novamente transformado no tempo, como nos diz Harvey:

Um ambiente físico criado em um determinado momento no tempo deve atender as necessidades daquela sociedade naquele momento determinado, mas tornar-se-á antagônico no futuro, na medida em que a dinâmica do processo de acumulação e o crescimento da sociedade alteram as necessidades de valor de uso tanto do capital quanto do trabalho. (1985b, p. 173)

Assim, um estudo sobre urbanização em qualquer formação social necessita que uma grande atenção seja dada às peculiaridades de sua dinâmica espacial e temporal. As considerações derivadas de um estudo de urbanização sob essa ótica afirmam, então, que a matriz urbana e o "ambiente racional" para o processo de acumulação são objetos de permanentes transformações. Nesse sentido, acumulação de capital, inovações tecnológicas e urbanização capitalista têm de andar juntas, havendo uma permanente inter-relação entre elas. A construção da infraestrutura física, sistemas de comunicação e centros de negócios formam a base potencial tanto para a circulação do capital como para a integração de todos elementos necessários à produção de mercadorias (incluindo trabalhadores assalariados) nos centros urbanos (Harvey, 1985b). 
Essa é, inevitavelmente, uma tarefa necessária para entender as especificidades de processos particulares de (re)estruturação urbana em qualquer lugar específico porque, como exemplifica Smolka,

A relação entre os processos de industrialização e urbanização nas sociedades capitalistas avançadas apresenta características que são bem distintas daquelas da periferia do sistema capitalista tomemos por exemplo Estados Unidos e Brasil. Isto por si mesmo é suficiente para sugerir que a formação da estrutura interna das cidades assume características bem diferentes nessas formações sociais. (1983, p. 4)

No entanto, em qualquer formação social, esses processos não se desenvolvem em um ritmo pacífico permanente; ao contrário, eles se desenvolvem através de um processo conflituoso, isto é, um processo competitivo, restringido pela intervenção do Estado, em resposta ao imperativo coletivo para reproduzir as exigências da (re)organização do espaço para a produção, circulação e consumo de mercadorias.

0 que emerge da retrospectiva analítica sobre a forma como o conceito tem sido utilizado e debatido é que, se pretendemos utilizá-lo como um conceito para explicar a periferização da classe trabalhadora no Brasil, uma importância maior precisa ser dada a ele em relação ao processo geral de produção e transformação das áreas urbanas de hoje.

\section{0 processo de produção e a transformação das áreas urbanas}

Todas as atividades humanas - finanças, diversão, serviços, comércio, habitação, indústria, agricultura - e as relacionadas à natureza (confinadas aos jardins botânicos e parques zoológicos, às reservas naturais ou aos parques nacionais) tornam-se usos do solo em determinadas zonas, apoiadas por construções apropriadas, regras, regulamentações e serviços. Isto é o espaço urbano: um produto histórico, do qual qualquer porção é objeto de relação dentro do sistema de relações que compõem o modo de produção e reprodução capitalista. "O espaço urbano é o espaço de um mercado unificado em uma economia de produção de mercadorias" (Deák, 1985, p. 105).

No entanto, as mudanças que têm sido produzidas nas configurações espaciais são problemáticas, pois o capitalismo necessita de infraestruturas fixas, produzidas como valores de uso específicos em lugares particulares, para facilitar a produção, troca, transporte e consumo de mercadorias. 0 capital necessita, portanto, estar representado na forma de um ambiente físico criado à sua própria imagem, através de valores de uso criados pelo trabalho humano e adicionados ao solo para facilitar a acumulação de capital futuro (Harvey, 1985b).

Para produzir um espaço econômico, 0 mercado unificado necessita de um espaço 
que seja suficientemente homogeneizado por uma infraestrutura de transportes e comunicação: vias, cabos, tubulações, redes aéreas e subterrâneas, etc., através dos quais objetos, informação e pessoas possam ir de uma localização para outra. Essas são estruturas físicas, uma infraestrutura coletiva. Somente então a relação entre duas localizações, da estrutura do espaço, ou finalmente o próprio espaço, pode se materializar.

Isso, em combinação com a tendência da monopolização econômica, é indubitavelmente uma das principais razões porque o Estado capitalista persistentemente se encontra na obrigação de suprir, não na forma de mercadoria, equipamentos urbanos na forma de investimentos de capital intensivo, fixo e indivisível tais como trens suburbanos, metrô, sistemas portuários, aeroportos, sistemas rodoviários, pontes, e assim por diante. 0 Estado torna esses itens inevitavelmente disponíveis para o usufruto geral (Scott, 1980).

Assim, a produção do espaço, a reprodução do espaço e o espaço de circulação representam os estoques básicos construídos da cidade contemporânea. Eles são os elementos funcionais essenciais de um sistema geográfico complexo, cuja evolução futura é amplamente dependente de sua interação interna. Mas essa evolução está longe de fluir facilmente de forma autorreguladora; ao contrário, ela continuamente enfrenta acidentes de percurso gerados internamente e que demandam intervenções coletivas imediatas na forma de planejamento.

Realmente, produção do espaço significa transformação do espaço, no sentido de que o produto final das intervenções no espaço não resulta em nenhuma estrutura particular (nova), mas simplesmente na transformação de uma estrutura particular existente. Estruturas físicas existentes podem permanecer intocadas por algum tempo, somente esperando para serem transformadas tão logo essa necessidade seja sentida. Mesmo enquanto elas permanecem inalteradas na sua forma física, essas partes da estrutura urbana podem ter seu valor de uso alterado, na medida em que o processo produtivo se desenvolve, como vimos anteriormente, em conexão como o valor de uso de localização.

Para manter o processo de acumulação, o processo produtivo requer uma incessante transformação do espaço; dessa forma os capitais investidos no ambiente urbano no passado vão sendo destruídos por novos investimentos, no presente. Por essa razão, o desenvolvimento capitalista tem de negociar uma linha divisória entre a preservação dos valores de investimentos passados embutidos no solo e sua destruição, de forma a oferecer um novo e eficiente espaço geográfico para acumulação. Uma luta permanente se dá, na qual espaços apropriados para as necessidades capitalistas são produzidos em um momento particular no tempo, somente para serem destruídos e transformados, usualmente no curso de uma crise, em um determinado momento no futuro (Harvey, 1985b).

A produção do espaço urbano é governada por leis distintas daquelas da produção de mercadorias simples, pelo fato de que ele não pode ser produzido como valor de uso individualizado. 0 capital investido no espaço urbano - abertura, pavimentação, iluminação de ruas, implantação ou extensão de redes de água, esgoto, assim como outras obras de infraestrutura urbana - atua como um capital fixo independente na medida em que ele não é um mero instrumento de produção no 
processo de produção, mas atua como uma pré-condição geral para a produção que pode ser utilizada individual ou coletivamente pelos capitalistas, de forma intermitente ou temporária (Harvey, 1984).

0 valor de uso do espaço é representado pelas localizações nele contidas, mas, sendo as localizações uma posição no espaço, elas não podem ser produzidas como tal. Assim, "o valor de uma localização é dado pelo tempo de trabalho socialmente necessário para produzi-la, ou seja, para produzir a cidade inteira da qual a localização é parte" (Villaça, 1998, p. 72).

Dessa forma, poderíamos dizer que qualquer intervenção em um determinado ponto no espaço provoca, em verdade, uma transformação em todo o espaço e, consequentemente, em todas as localizações nele contidas. Isso significa que um quantum do poder produtivo da sociedade (trabalho abstrato) é devotado à produção de uma soma total de mudanças da infra e supraestrutura física necessária para adaptar o espaço urbano às necessidades da produção e reprodução de mercadorias.

Assim, como diz Deák (1985), o preço de uma localização é consequência das necessidades de organização do espaço para produção e consumo de mercadorias e de acordo com as condições de competição dominantes entre os capitais.

Na medida em que a mercantilização e, com ela, a regulação do mercado não podem ser generalizadas para toda a economia capitalista, as condições de competição são circunscritas pela intervenção do Estado. Se o fluxo de capital entre empresas e indústrias é regulado (em maior ou menor grau de acordo com o estágio do processo de acumulação), através de taxas, subsídios, intervenção direta e regulamentações que afetam a concentração e centralização de capital, controles nacionais e assim por diante, também a localização espacial é controlada por leis de zoneamento, taxas de propriedade, etc. (Deák, 1985).

A regulação da produção é assim conseguida, em uma primeira instância, pelo mercado e, em uma segunda instância, pela consciente e planejada intervenção do Estado, guiado pelos sinais emitidos pela economia de mercado.

Assim, para entender - e desenvolver uma análise sobre - gentrificação é necessário colocar a análise no contexto no qual o processo se desenvolve. A análise deveria ser direcionada não apenas ao estudo da geografia econômica, isto é, da espacialização dinâmica da produção de mercadorias como tal, mas ligando-a também ao estudo dos processos de uso do solo para habitação.

É a possibilidade de reinserção de qualquer área urbana, com características funcionais e espaciais específicas, no processo de produção e consumo, que a torna de interesse para alguns setores da economia. No entanto, essa possibilidade torna-se efetiva somente quando as condições necessárias para a performance de certas funções novas são estabelecidas, através de investimentos privados ou sociais. A incorporação de uma área urbana (ou sua reincorporação com um novo status) é usualmente feita através de alguma forma de intervenção planejada com o propósito de superar barreiras que possam inibir sua utilização lucrativa.

Assim, a forma usual de possibilitar que um programa de renovação urbana seja lucrativo é aumentar substancialmente o status de uma área, dando a ela uma nova configuração 
física. A formação e a possibilidade de apropriação daqueles benefícios por uma camada social mais rica significam, no entanto, a exclusão dos ocupantes anteriores daquela área, isto é, sua erradicação.

Essa realidade parece ser um clichê na dinâmica do dia a dia da maioria das cidades capitalistas (pelo menos enquanto prevalecerem as relações sociais capitalistas). No entanto, a origem dos padrões de segregação contemporâneos nas cidades deriva do desenvolvimento de mudanças econômicas e sociais que aconteceram no passado. Essas mudanças estão relacionadas a alterações na estrutura no mercado de trabalho, à crescente divisão social e diferentes consequências associadas a elas, à crescente separação entre camadas sociais na maioria dos períodos históricos e à estrutura de preços do solo. Como corolário poderia ser dito que a hierarquia do uso do solo urbano e a estrutura de distribuição de riqueza, característicos do capitalismo, tornam quase impossível encontrar um padrão paralelo de desenvolvimento urbano em formações sociais distintas (McDowell, 1982).

\section{0 processo de gentrificação na dinâmica da (re)organização urbana na Europa, Estados Unidos e Canadá}

Como indica a literatura, o final dos anos 1970 presenciou a percepção do fenômeno descrito como de gentrificação - como parte do processo de renovação urbana - em uma grande quantidade de cidades, especialmente nos Estados Unidos e na Inglaterra, e também no
Canadá (Hamnett, 1984). A reação a esse processo, nesses países, tem sido muito variada, mas de forma quase unânime ele tem sido saudado como o salvador da decadência das áreas centrais das cidades e, mais comumente, revelado como um agente de desalojamento da classe trabalhadora.

Que o processo de gentrificação resulta em alguma forma de desalojamento da classe trabalhadora não há dúvida, e isso é um indicativo da fraca posição das camadas sociais de mais baixa renda no mercado da habitação; se em um determinado momento elas estiveram concentradas na área central das cidades, em razão de seu pequeno poder de compra, estão agora sendo novamente desalojadas pela mesma razão. Como bem observa Ley, "o mercado que prejudicou os mais desprovidos pela falta de investimentos nas áreas centrais das cidades industriais está penalizando o mesmo grupo, no presente, através de investimentos em excesso" (1981, p. 144).

As maiores cidades dos Estados Unidos presenciaram, até o final dos anos 1950, e na Europa ainda até mais tarde, um processo de suburbanização em decorrência do qual algumas atividades econômicas, especialmente aquelas ligadas à indústria manufatureira, começaram a abandonar as localizações mais caras das áreas mais centrais (poluídas e altamente densificadas), aproveitando as vantagens (custos menores e áreas maiores) do subúrbio (Scott, 1980).

0 movimento centrífugo de empresas e população gerou um efeito multiplicador: a crescente descentralização de empresas encorajou ainda mais a suburbanização de famílias de camadas alta e média, com a construção de comunidades suburbanas, como novas cidades 
em solo barato, enquanto as habitações dilapidadas e velhos prédios industriais no centro da cidade foram ocupados por famílias de baixa renda - arrendatários ou proprietários.

Segundo Scott (1980), pelos meados dos anos 1950, especialmente nos Estados Unidos, o abrupto processo de expansão suburbana já estava começando a enfrentar inúmeros problemas, muitos deles relacionados ao transporte. 0 carro privado, que, em uma primeira instância, sustentou o processo de crescimento periférico, estava agora começando a encontrar limites reais para sua utilização e eficiência. A rede de vias e rodovias existentes, ligando as distantes comunidades suburbanas ao centro da cidade, onde uma significativa proporção de moradores suburbanos continuava a trabalhar, era inadequada às crescentes demandas que estavam agora se apresentando.

Assim (particularmente nos Estados Unidos), massivos programas de construção de vias expressas foram implementados, encorajando dessa forma, ainda mais, a expansão suburbana e a utilização do transporte individual (e produzindo, como consequência, formidáveis congestionamentos e problemas de estacionamento no centro das cidades). Uma síndrome foi então criada, segundo a qual vias expressas aumentavam a necessidade de mais vias expressas. Essa síndrome parecia não ter mais fim, e a saída das empresas e famílias do centro das cidades para os subúrbios continuou deixando para trás um resistente resíduo de famílias trabalhadoras (caracterizadas por altos níveis de pobreza e desemprego), vivendo em bairros decadentes distribuídos em torno das áreas mais centrais da cidade. Como diz Scott:
À medida que as empresas e as famílias migravam em número crescente, no sentido do centro da cidade para o subúrbio, 0 centro começou a entrar em um processo de decadência e dilapidação. Este processo posteriormente desabou sobre ele mesmo. Ondas de miséria se expandiram a partir dos epicentros de decadência, e como o emprego para trabalhadores de baixa qualificação tornou-se cada vez mais escasso, houve um correspondente crescimento de pobreza e desemprego nos bairros centrais de trabalhadores. Pegos neste auto-alimentado círculo vicioso, os proprietários de terra urbana não puderam fazer muito mais do que estimular toda esta dinâmica de deterioração das áreas centrais urbanas, restringindo todo e qualquer novo investimento improdutivo em bairros decadentes, e explorando as suas propriedades da melhor forma possível a curto prazo. A consequência foi uma crescente ineficiência na alocação de terras nas áreas centrais das cidades, uma redução crescente da renda municipal, e um grande efeito explosivo negativo emanando das favelas das áreas centrais da cidade, ameaçando perturbar a ordem geral da vida urbana estabelecida. (1980, pp. 212-213)

Nos Estados Unidos (e, em menor grau, na Grã-Bretanha), a fuga das áreas centrais das cidades foi muito mais marcante do que, por exemplo, no Canadá. Nos casos dos Estados Unidos e Inglaterra, apesar do grande sucesso dos altamente concentrados Central Business Districts - CBDs, as áreas centrais como um todo passaram a apresentar sinais de uma severa crise financeira municipal quando a abrupta migração de empregos e pessoas para os subúrbios provocou uma contínua erosão da arrecadação local. Esse fenômeno determinou inevitavelmente a deterioração da infraestrutura 
das áreas centrais das cidades e também do nível dos serviços urbanos em geral, e isso, por seu turno, produziu ainda mais futuros rounds de migração para a periferia.

Esse processo de expansão periférica, estabelecido por um bom tempo, começou a esmorecer à medida que os fundos públicos continuaram a "secar" nos anos 1970, não somente nas áreas centrais (onde a crise era mais severa), mas em todos os lugares. Ainda mais que cada incremento na expansão da área suburbana custa geometricamente mais (em termos de custo social total) do que o incremento anterior. ${ }^{5}$

Assim, nos anos 1970, o até aqui prevalente e agressivo processo de expansão periférica estava, ele mesmo, sendo sufocado pela retração dos dispêndios públicos em infraestrutura na periferia urbana. Em resposta a essas circunstâncias e também a pressões de ambientalistas, as políticas públicas nos Estados Unidos e também na Inglaterra se orientaram na direção de, definitivamente, conter a expansão urbana e (contrariamente às principais correntes das políticas anteriores) voltar-se para a revitalização das áreas centrais das cidades, redirecionando o crescimento da periferia para o centro da cidade (Scott, 1980).

Os programas de renovação urbana nos países já citados, nas décadas de 1950 a 1970, passaram a dar suporte e a reanimar o comércio. Segundo Scott:

Este fenômeno estava predominantemente relacionado ao mercado privado e ao estabelecimento hegemônico das áreas centrais das cidades como distritos de negócios e empregos para mão de obra qualificada. Como resultado, um característico e dispendioso padrão de viagens interurbanas diárias começou a surgir. De um lado, trabalhadores qualificados trafegavam do subúrbio para as áreas centrais. De outro lado, trabalhadores sem qualificação trafegavam do centro da cidade para as novas áreas industriais do subúrbio. Desta forma, mais vias expressas e estacionamentos tiveram de ser adicionados nas áreas centrais da cidade de forma a acomodar este dispendioso padrão de transporte. Concomitantemente, porções do já reduzido estoque de habitação de baixo custo no centro da cidade eram destruídas para dar lugar à contínua expansão das atividades comerciais, avenidas e estacionamentos. (1980, p. 57)

Na medida em que 0 acesso de transporte às áreas centrais da cidade ( $C B D s)$ vinha sendo melhorado em relação ao restante do sistema urbano, nos anos 1950 e 1960, o preço do solo nas localizações centrais também aumentou. Em termos gerais, essa escalada de preços resultou em um conjunto de consequências aparentemente contraditórias. De um lado, uma insistente tendência na intensificação e densificação de uso do solo; de outro, a formação de um estoque de terras em antecipação a possíveis ganhos futuros, atrasando o desenvolvimento, tornou-se um fenômeno comum (Scott, 1980).

Com a diminuição da oferta efetiva, a retenção de terras determina uma elevação dos preços do solo ainda maior, produzindo ainda mais intensificação do uso do solo nas áreas centrais. Dado que as empresas localizadas nos CBDs tendem a ter uma estrutura baseada em mão de obra intensiva, elas colaboram para os problemas existentes no centro da cidade, na medida em que induzem à intensificação e, portanto, ao 
congestionamento do tráfego. Dessa forma, elas exacerbam a escassez das áreas de estacionamento, ajudam a criar mais sobrecarga no transporte público e assim por diante. 0 poder público foi forçado, portanto, a debruçar-se sobre a questão do inadequado acesso do transporte às áreas centrais da cidade, produzindo a intervenção, via planejamento, na forma de melhorias na capacidade do transporte e de serviços. Essas melhorias aumentaram as vantagens locacionais do $C B D$, e isso, por sua vez, determinou mais uma vez o aumento dos preços do solo, criando assim novos rounds de intensificação do uso do solo nessas áreas da cidade (Scott, 1980).

Segundo Marcuse (1986), como resultado dessa intensificação do uso do solo no centro das cidades, duas formas características de pressão entraram em jogo nos velhos bairros residenciais que o circundam. Primeiro, na medida em que os preços do solo sobem no centro, surge uma pressão para transformar as áreas residenciais de população de baixa renda, situadas imediatamente em torno dele, em zonas comerciais e de serviço. Segundo, à medida que a proporção de emprego qualificado cresce em detrimento do emprego de baixa qualificação no centro, um número significativo de famílias de classe média e alta estará pronto para adquirir e renovar as velhas casas dos bairros de baixa renda, próximos ao centro, e os investidores estarão prontos a fazer o mesmo para revendê-los no mercado.

Ambos os tipos de pressão são uma ameaça de desalojamento das famílias de baixa renda. 0 conflito é inevitável, dada a restrita disponibilidade de habitação de baixa renda em outros lugares no sistema urbano. Essas pressões resultam, então, em confrontações políticas e no esfacelamento de velhas localidades urbanas com um alto grau de coesão social (Marcuse, 1986).

Quando uma família percebe que sua vizinhança está se transformando drasticamente, quando todos os seus amigos estão saindo, quando lojas estão sendo fechadas, e novas lojas para outra clientela estão tomando seus lugares (ou nenhuma outra está tomando seu lugar), quando mudanças nos serviços públicos, no transporte, etc., estão tornando a área cada vez menos habitável, então a pressão para o desalojamento já é severa, e é somente uma questão de tempo para que ele se concretize.

Como sugerem Hawley e Duncan (1957), o estrato social de baixa renda é o mais afetado por esses programas de renovação urbana. De acordo com o autor, o desenvolvimento das grandes e modernas cidades tem sido acompanhado por um extraordinário processo de valorização do solo especialmente situado no centro da cidade. À medida que os velhos prédios, situados no centro, não mais correspondem às novas necessidades demandadas para aquela localização, eles são demolidos e substituídos por novos.

0 processo de gentrificação nesses países se desenvolve mais ou menos da seguinte forma: o êxodo das camadas sociais mais ricas, como resultado da deterioração física do ambiente construído, facilita a ocupação da área pelas camadas sociais de menor renda. Assim, os edifícios existentes são adaptados pelos proprietários, basicamente para aumentar a densidade de ocupação, permitindo a acomodação de um número maior de famílias na mesma área, em unidades menores, gerando assim mais retorno por metro quadrado. 0 objetivo é aumentar os retornos 
financeiros pela multiplicação do número de ocupantes. Por outro lado, o proprietário reduz quase todos os investimentos em melhorias e manutenção, na medida em que, como resultado da baixa expectativa em relação à qualidade do imóvel e da pouca capacidade de pagamento entre os novos moradores, a racionalidade do sistema permite a apropriação de maiores retornos financeiros mesmo em um processo de degradação.

Essa condição de centralidade leva a uma contradição entre o processo de degradação do ambiente construído e a valorização do solo nesses lugares. Tendo em mente que as possibilidades de aquisição dos novos ocupantes são bem restritas, o proprietário está certo de que ele poderá sempre encontrar interessados em grande quantidade na medida em que sempre haverá um grupo de pobres e novos trabalhadores procurando emprego e moradia de baixo custo. A maioria dos estudos nos Estados Unidos e na Europa coloca essa situação como uma pré-condição para o processo de gentrificação.
Nos Estados Unidos, Inglaterra e Canadá, gentrificação é descrito como um processo de renovação urbana do centro deteriorado de algumas de suas maiores cidades, ocorrido de 1950 em diante. As intervenções, públicas e privadas, aparecem na forma de ações nas áreas centrais da cidade, de forma a mudar sua configuração espacial e melhorar a qualidade dos prédios e serviços públicos e privados, para atender as demandas de uma nova e mais rica população. No entanto, essa transformação não surge sem trauma social. Transformações são normalmente precedidas tanto pela demolição de velhos prédios (residências, indústrias e depósitos), quanto pela erradicação de seus ocupantes de baixa renda para os subúrbios. Assim, se de um lado o processo tem sido alardeado como o salvador das áreas centrais decadentes, de outro ele tem sido revelado como um agente de desalojamento das classes trabalhadoras.

Assim, nos Estados Unidos, Europa e Canadá, o processo de gentrificação pode ser sumariado de acordo com o esquema apresentado na Figura 1.

Figura 1 - O processo de gentrificação na dinâmica da (re)organização urbana nos Estados Unidos, Europa e Canadá

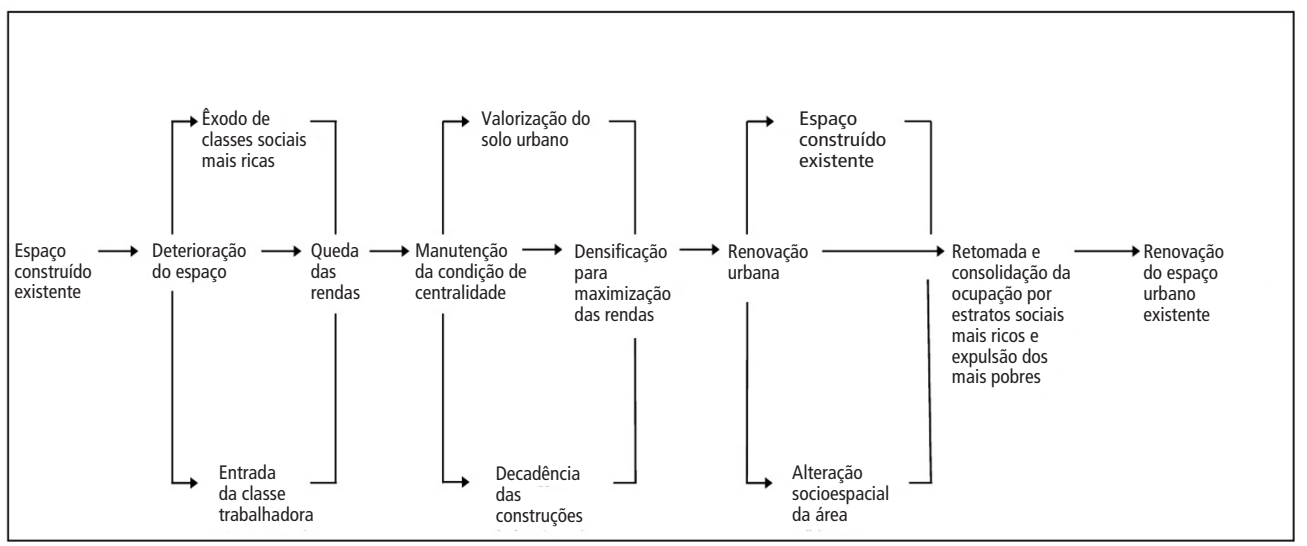




\section{0 processo de gentrificação em Dona Teodora na dinâmica da (re)organização urbana em Porto Alegre}

De acordo com o que até aqui foi exposto, "Dona Teodora" oferece um interessante exemplo de gentrificação para o entendimento do fenômeno em um contexto diferente dos que, até o presente momento, foram mais estudados.

0 desenvolvimento de "Dona Teodora" foi, em parte, resultado da densificação e do consequente aumento dos preços do solo no centro da cidade de Porto Alegre a partir da década de 1940. Esses dois aspectos forçaram o deslocamento de boa parte das indústrias que aí se situavam para os subúrbios da cidade, como o "Arraial dos Navegantes", cedendo seu espaço anteriormente ocupado no centro, especialmente para a expansão do setor terciário.

Desde o início da ocupação do "Arraial dos Navegantes", um processo de segregação já aí se configurava, dividindo a área em dois setores: um, com cota de terreno mais alta, ocupado pelas indústrias, e, portanto, menos sujeita a alagamentos, e um outro ocupado [invadido] por trabalhadores, procurando moradia perto dos locais de trabalho, residindo em malocas, na parte norte da área onde as enchentes eram frequentes.

As áreas invadidas em "Dona Teodora" durante muito tempo não foram disputadas por outras camadas sociais, por não terem outra utilidade que a de depósito e queima do lixo da cidade. 0 descontrolado número de 16.686 moradores irregulares, já aí existentes em 1965, levou toda a área a uma estagnação social e econômica.
0 processo de gentrificação em "Dona Teodora" foi longo e descontínuo, envolvendo ao longo de mais de quarenta anos toda sorte de ações. 0 processo teve dois momentos importantes: um durante a década de 1960, a partir do projeto Humaitá, e outro que iniciou com a implantação do projeto Humaitá-Navegantes, no início dos anos 1990.

Com a construção de um dique em 1969 (como parte das primeiras intervenções) a área passou a ter proteção contra as frequentes enchentes. Essa nova situação deu algum valor comercial àquelas áreas ocupadas por malocas, até então inundáveis, justificando novos investimentos para equipar a área com uma boa infraestrutura e, assim, atrair novas indústrias para estes locais. Assim, muitos investimentos se seguiram: foram abertas várias avenidas, obras de saneamento, lazer (praças e parque) e, também, a instalação de equipamentos públicos. $\mathrm{A}$ área adquiriu um novo status e teve, assim, aumentado consideravelmente seu valor.

Além da erradicação via forças de mercado, a remoção direta pelo uso da força (a partir da metade dos anos 1960 até o início dos anos 1980), ação de despejo, persuasão e negociação (especialmente a partir dos anos 1980), estiveram entre as várias iniciativas utilizadas para promover a erradicação dos moradores de baixa renda vivendo em assentamentos irregulares em "Dona Teodora", cada alternativa predominando de acordo com as especificidades do momento político.

Até os anos 1980, os processos de remoção se desenvolveram, quase sempre, através de iniciativas conjuntas, envolvendo diversos atores: Prefeitura de Porto Alegre, Conselho do Plano Diretor do Município, DEMHAB, Câmara de Vereadores e outros agentes tais como 
empresários e incorporadores que, organizados na associação dos empresários e, também, na associação de moradores do bairro Humaitá, tinham interesse em dar uma nova ocupação para a área.

Não existe, no entanto, uma divisão clara entre os períodos segundo a utilização desta ou daquela forma de erradicação. Muitas vezes elas foram utilizadas simultaneamente. Mesmo antes do final do período mais repressivo do regime militar, variadas formas de ação, com vistas à desocupação das áreas ocupadas irregularmente, foram utilizadas. É importante salientar, no entanto, que o único período em que as erradicações sofreram algum tipo de resistência foi durante o período mais repressivo do regime militar quando as remoções eram efetuadas pela força com a demolição, ou mesmo queima, das malocas. Após esse período, as remoções pela força foram dando lugar às outras formas de intervenção, via justiça ou negociação, e assim os conflitos, o uso da força e os embates corporais foram gradativamente sendo evitados.

À medida que o poder militar enfraquecia, as negociações para erradicação, ou mesmo regularização de assentamentos irregulares, tornaram-se as alternativas cada vez mais utilizadas pela Prefeitura para lidar com o problema de áreas com ocupação irregular.

Seja como for, a partir do final da década de 1970, a atitude em relação às áreas invadidas sofreu uma mudança radical. Negociação política e cautela tornaram-se práticas comuns. Assim, novas estratégias de pressão foram utilizadas. Em 1988, os empresários locais iniciaram um movimento para emancipar o bairro e transformá-lo em um novo município da Região Metropolitana onde eles tivessem mais poder. No mesmo ano, a empresa Primorosa entrou na justiça em uma disputa contra os residentes irregulares da Vila Santos Guerra, uma das últimas vilas remanescentes situadas em uma localização valorizada de "Dona Teodora".

A partir das melhorias na infraestrutura, a possibilidade de expandir a ocupação industrial na área tornou-se uma realidade e, assim, a remoção de parte da população de trabalhadores que ainda aí moravam em malocas passou a ser de interesse público. A designação pelo $1^{\circ}$ PDDU (Plano Diretor de Desenvolvimento Urbano), em 1979, das áreas de "Dona Teodora" para uso predominantemente industrial ${ }^{6}$ foi o primeiro passo nesse sentido. Essa designação foi um instrumento, técnico e político, importante para desestabilizar as ocupações irregulares e, portanto, erradicá-las tendo em vista que sua ocupação passou a estar em desconformidade com a legislação, não havendo portanto, segundo o poder público local, possibilidade de regularizá-las.

A primeira tentativa de atrair uma nova classe social para "Dona Teodora" deu-se entre 1980/84 quando 2.505 apartamentos para a classe média foram construídos em áreas já desocupadas. Sua comercialização foi, no entanto, difícil tendo em vista a existência de malocas na vizinhança. Como consequência, uma boa parte dos apartamentos não comercializados foi invadida por trabalhadores sem teto, levando a que muitos compradores abandonassem seus apartamentos.

As intervenções prosseguiram, e entre os anos de 1996 e 1999 foram realizados trabalhos de terraplenagem para subir a cota de terreno de algumas áreas anteriormente ocupadas por malocas para, enfim, permitir seu uso para fins comerciais. Nessa época a área 
já estava consolidada pela ocupação predominantemente comercial, mais vilas haviam sido removidas e o risco para mais invasões ficava muito difícil tendo em vista a pressão exercida pela Associação dos Empresários do Bairro Humaitá, já bem consolidada nessa época, sobre o poder público. Com isso tornou-se possível a retomada do lançamento de habitações para a classe média no bairro. Em 1990, os apartamentos invadidos nos edifícios construídos durante a década de 1980 foram retomados por via judicial e renegociados. A porta para a expansão da ocupação pela classe média estava definitivamente aberta.

No final de 1994, o shopping DC Navegantes foi construído, e em 1999, concluída a primeira etapa de um novo programa residencial, executado pela Construtora Titton Burgger, sob a forma de um condomínio multifamiliar, também para famílias com renda superior a 10 SM. Na primeira fase do projeto, todos os 256 apartamentos foram comercializados no mesmo ano, e uma nova fase com o mesmo número de apartamentos, concluída em 2001, também está totalmente comercializada.

Em 2002, a Self Engenharia concluiu dois condomínios horizontais: o Jardim Lirius e o Tulipas Residence, com um total de 350 casas de dois e três dormitórios, salão de festas, academia de ginástica totalmente equipada, quadra poliesportiva e portaria 24 horas, para uma população estimada em 1.200 pessoas), também fazendo parte desse investimento a construção de uma área comercial com dez lojas. Importante salientar que esse novo empreendimento já fora direcionado para famílias com renda de 15 ou mais salários mínimos.

Em 2003, a Construtora Self Engenharia lançava mais um condomínio horizontal, o
Alqueires Residence, ao lado dos dois condomínios concluídos em 2002. As unidades habitacionais contariam com uma suíte americana, dois dormitórios, web star, lavabo e pátio individual com espaço para churrasqueira. 0 empreendimento teria sala de ginástica equipada, piscina, salão de festas e quadra poliesportiva.

Como vimos, foram os investimentos em infraestrutura para consolidar a área como zona de comércio e serviços que possibilitaram a mudança de status de "Dona Teodora", expulsando a população de baixa renda morando irregularmente, para então dar lugar à habitação para classe média. Todas as tentativas de implementação de moradia para classe média efetuadas na década de 1980 foram frustradas pela presença das malocas. Para isso, no entanto, a estratégia foi transformar parte da área como zona de uso industrial e assim tornar incompatível o uso residencial.

Em Porto Alegre, como no restante do Brasil, a localização industrial tem sido um fenômeno predominantemente da periferia urbana, e a habitação de baixa renda tem seguido dois diferentes padrões: o cortiço e a favela, com localizações predominantemente distintas. 0 cortiço é uma forma de moradia individual ou coletiva, usualmente arrendada, estabelecida em velhas e decadentes edificações. No Brasil, eles seguem um padrão muito similar àqueles descritos nas áreas centrais das cidades nos Estados Unidos e na Europa, e em Porto Alegre estão espalhados pela área urbana mais central da cidade. Eles são, predominantemente, bem localizados em relação aos locais de trabalho e com acesso aos principais serviços urbanos (água encanada, eletricidade, coleta de lixo). A ocupação densa e decadente representa o custo social dos cortiços. 
Favelas, ou "malocas", como elas são melhor conhecidas em Porto Alegre, são caracterizadas por aquelas habitações localizadas predominantemente na periferia da cidade e assentadas em áreas públicas ou privadas invadidas. Elas são uma forma barata de habitação, e seus ocupantes estão concentrados entre os grupos de menor renda da força de trabalho. Favelas são, de acordo com a definição oficial da Prefeitura de Porto Alegre, "grupos de pequenas habitações construídas com material inadequado (madeira, zinco, lata, papelão, etc.) distribuídos irregularmente, quase sempre em áreas não servidas por serviços e infraestrutura urbana" (PMPA/DEMHAB, 1998, p. 89).

Por trás desse tipo distinto de segregação da habitação da classe trabalhadora está um processo bem caracterizado de desenvolvimento urbano, que mostra uma distinção fundamental em relação aos exemplos dos Estados Unidos, Inglaterra e Canadá.

Em Porto Alegre, a ocupação ilegal das áreas privadas ou públicas desocupadas pela classe trabalhadora permite a reprodução da força de trabalho a baixos custos de reprodução, na medida em que se torna desnecessário incorporar ao salário dessa massa de trabalhadores os custos de moradia, isto é, habitação mais os serviços urbanos providos pelo Estado: água encanada, energia elétrica, coleta de lixo e sistema de esgoto. Os favelados utilizam esses serviços também ilegalmente, através de ligações clandestinas.

A manutenção das situações irregulares permite uma estrutura urbana mais flexível para o futuro, facilitando - quando necessário - a erradicação dos moradores, tão logo os setores mais ricos da sociedade, em especial aqueles diretamente ligados à produção imobiliária, se interessem por aquela localização para futuros lucros ou uso imediato. Além disso, em contraste com os muito documentados exemplos dos Estados Unidos, Inglaterra e Canadá, os investimentos para melhoria e renovação das áreas urbanas ocupadas pela classe trabalhadora, no Brasil, têm sido predominantemente efetuados pelo Estado. 0 Estado tem sido o grande agente, tanto no que diz respeito ao desenvolvimento urbano quanto à remoção de favelas.

As intervenções públicas têm sido de grande valor para todos aqueles capacitados a investir subsequentemente no espaço, apropriando-se, assim, de todos os benefícios relativos a uma boa localização. Assim, as intervenções do Estado criam, através do tempo, as condições para a apropriação do solo por aqueles grupos específicos habilitados a pagar o novo preço de localização correspondente a seu novo valor de uso.

0 processo de gentrificação na cidade de Porto Alegre afetou tanto os cortiços quanto as favelas. No entanto, o processo de gentrificação dos cortiços foi muito mais um processo de renovação, restrito à reabilitação de edificações velhas e fisicamente decadentes, ou - aqui e ali - pela demolição e reconstrução de novas unidades individuais. Nesse caso, a transformação segue o mesmo esquema não mediado apresentado por Merrett (1976). A quantidade de capital envolvido no processo não é relevante, na medida em que o capital adiantado pelo novo morador é apenas para pequenas reformas. Não há, portanto, o grande capital especulativo envolvido. A escala é, assim, insignificante para uma eventual transformação de um bairro ou mesmo de um setor urbano.

Pela razão de os cortiços estarem situados em áreas urbanas com praticamente toda a 
Figura 2 - O processo primário de gentrificação na dinâmica da (re)organização urbana no Brasil

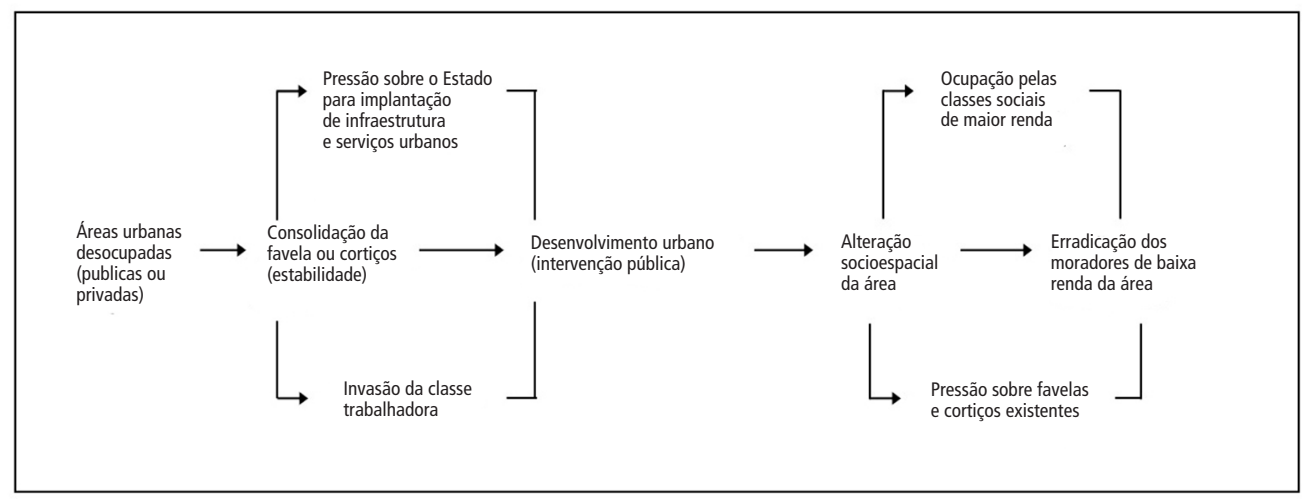

infraestrutura e serviços urbanos instalados, a demanda por esses tipos de edificação vem de setores da sociedade que não são os mesmos das favelas. Poderíamos denominar esse caso, pela sua insignificância para grandes transformações urbanas, como um processo secundário de gentrificação.

0 processo primário de gentrificação em Porto Alegre deve ser relacionado a processos de (re)desenvolvimento urbano, com a intenção de erradicar habitações de baixo custo - favelas - para transformar o uso do solo em uma escala de grandeza que não se restrinja apenas à transformação de um conjunto de habitações inseridas em um quarteirão, mas tenha importância para a transformação do status de um bairro ou mesmo um setor urbano.

0 esquema apresentado na Figura 2 representa o processo primário de gentrificação em Porto Alegre.

\section{Conclusão}

0 conceito de gentrificação tem, para nós, um poder explicativo para ser aplicado ao processo de periferização da classe trabalhadora em Porto Alegre. Para isso é preciso, no entanto, abandonar a ideia de gentrificação como um processo de simples troca de moradias de população de baixa renda e outras edificações (como, por exemplo, depósitos) por moradias para população de renda média e alta no centro das cidades. Nossa proposição é a de que o conceito de gentrificação necessita ser relacionado a processos mais amplos de (re)estruturação urbana. Pesquisas passadas, apesar de desvendarem uma variedade de formas, processos e mecanismos, desenvolveram somente explicações diferentes para o mesmo modelo de gentrificação. 
De acordo com essa proposição, o processo de gentrificação deveria ser analisado como o resultado do permanente processo de (re)organização urbana nas cidades capitalistas modernas, necessário ao contínuo processo de acumulação de capital, através do qual áreas urbanas deterioradas, ocupadas pela classe trabalhadora, podem ser ocupadas por outros setores da sociedade (camadas sociais de renda alta e média), não somente para habitação, mas para a instalação de outros usos também.

Nós sustentamos, portanto, que produção do espaço hoje em dia significa (re)organização do espaço urbano existente para atender às necessidades dos processos de produção e consumo existentes. No entanto, a (re)organização do espaço está longe de ser um processo autorregulado e que se desenvolve sem percalços; ao contrário, ele continuamente enfrenta dificuldades, geradas internamente, que clamam pela intervenção do Estado.

A disputa pelo espaço revela uma grande competição no mercado imobiliário, que emana da interação complexa de forças sociais, políticas e econômicas, as quais determinam diferentes tipos de segregação nos quais o Estado joga um papel controverso na tentativa de resolver as mais variadas situações de conflito. Essa organização implica a atribuição de níveis de preferência diferenciados para cada uso do solo, de maneira que ele contenha uma estrutura hierárquica, de acordo com a qual cada uso terá uma preferência sobre o outro. Os níveis de hierarquia não correspondem a uma hierarquia econômica absoluta, mas às necessidades da produção em termos de organização espacial e do poder de barganha que cada usuário tem sobre esse espaço.
Mas a produção do espaço urbano significa, cada vez mais, a transformação do espaço, no sentido de que o produto final das intervenções no espaço não é uma nova estrutura em particular, mas a transformação da própria estrutura existente. No entanto, a produção do espaço urbano é dirigida por regras distintas daquelas da produção de bens simples de consumo, pelo fato de que o espaço não pode ser produzido como um valor de uso individualizados. Qualquer intervenção em uma porção particular de espaço leva a uma transformação de todo o espaço e, em última análise, de todas as localizações que o compõem. A produção de localizações urbanas é efetuada no nível coletivo e, como parte da produção do espaço urbano, como um todo. Assim, a determinação da escoIha de uma (re)localização, aberta ao processo individual de produção, depende da estrutura do espaço urbano como um todo.

A determinação da escolha de localizações, postas à escolha das unidades individuais de produção, pode resultar, no entanto, em uma situação de conflito entre grupos relativamente homogêneos de usuários, os quais não podem ser resolvidos nesse nível: um grupo de usuários quer se mover (e também se confinar em grupo) em localizações ocupadas por outro grupo de usuários, que não querem deixar sua localização. Essa situação dá lugar a grupos de interesse rivais. Uma confrontação direta resultaria em um crescimento anárquico, o que força a entrada do Estado no processo.

Assim, a intervenção do Estado é necessária e inevitável. Algumas consequências disso para o processo individual de produção aparecem na forma de taxação e confinamento do padrão de assentamento em 
determinadas localizações, determinadas pelo zoneamento e outras regulamentações que asseguram sua compatibilidade com um padrão geral de assentamento.

Nesse sentido, as autoridades públicas podem colocar interesses restritivos ao uso do solo de forma a proteger algumas áreas de ocupantes ou mesmo para a exclusão de alguns grupos sociais indesejáveis. Da mesma forma, bancos, promotores urbanos (privados ou públicos), capitalistas industriais podem, de acordo com - ou manipulando - a lei, operar uma alocação desigual de recursos a diferentes partes da área urbana, iniciando, ou reforçando, desigualdades intraurbanas. Tais desigualdades emergem de políticas governamentais locais de zoneamento, seleção de moradores para alocação de determinadas áreas, relocalização de moradores irregulares, provisão de espaços de lazer e localização de escolas e demais usos urbanos, em relação ao transporte público. Ações e mecanismos desse tipo muitas vezes modificam, amplificando ou reduzindo, as desigualdades de renda geradas na economia.

Assim, o regramento do uso do solo é resultado do uso conjunto de vários meios de regulamentação, que são postos em prática para assegurar que atividades sejam localizadas de acordo com uma hierarquia de usos do solo e de classes. Nesse processo, a distribuição desigual de renda produz uma competição desigual no mercado. Desigualdade que não resulta somente das forças econômicas, mas, como vimos, de um complexo inter-relacionamento de forças sociais, políticas e econômicas.

Frequentemente, a única forma de tornar um programa de renovação urbana lucrativo é a de aumentar substancialmente o status social de uma área ligada a uma nova configuração física. Na medida em que uma área urbana é beneficiada por investimentos públicos e esses investimentos aumentam o preço (valor) daquela terra, é esperado que algumas alterações na composição social da população residente venha ocorrer. Alterações naquela composição podem acontecer pela expulsão de famílias incapazes de enfrentar a nova realidade de preços (aluguéis, por exemplo) e outras novas despesas relacionadas às melhorias (taxas, impostos, tarifas), e principalmente pela atração de um novo estrato social economicamente mais poderoso, que passa a pressionar por mais investimentos (melhorias) e pela expulsão dos setores sociais indesejáveis.

Portanto, se o espaço urbano é segregado em uma relação direta à alocação desigual dos investimentos públicos, podemos dizer que a razão pela qual a classe trabalhadora é segregada na periferia (ou mesmo em áreas centrais) das cidades não pode ser explicada somente em termos da competição anárquica entre estratos sociais, tendo o nível de renda como único parâmetro, já que ela está diretamente relacionada à forma como o Estado intervém no espaço.

A experiência de "Dona Teodora" propicia um claro exemplo de gentrificação, cultivado com o auxílio de políticas públicas, em uma cidade que vem reduzindo suas atividades industriais e dando lugar a atividades econômicas ligadas a comércio e, principalmente, serviços. Como vimos em "Dona Teodora", essas atividades lideraram, através da Associação dos Empresários do Bairro Humaitá, ao invés de seguir a reocupação do espaço. A classe média, que não tinha organização e poder político para demandar com sucesso as 
transformações habitacionais pretendidas para a área, foi, no início, mera espectadora.

Nesse sentido, o processo de gentrificação em "Dona Teodora" está relacionado não somente às desigualdades sociais e à mobilidade social, determinando novas formas de vida, mas, essencialmente, como tentamos demonstrar, ao processo de produção e consumo e às respectivas transformações que ele produz sobre o espaço e em seus valores de uso. Assim, deve-se entender os mais diversos processos de gentrificação como facetas de processos distintos de (re)estruturação urbana, de acordo com os requerimentos do desenvolvimento da produção e consumo capitalistas. Dessa forma, gentrificação aparece como uma das possíveis consequências do permanente processo de organização espacial, ou seja, o processo permanente de produção do espaço em atendimento aos ditames da economia.

\section{Carlos Ribeiro Furtado}

Universidade Federal do Rio Grande do Sul, Faculdade de Arquitetura e Urbanismo, Departamento de Urbanismo. Porto Alegre/RS, Brasil.

carlosfurtado53@gmail.com

\section{Notas}

(1) O termo gentrification foi criado em 1964 por Ruth Glass para descrever o processo que teve início nos anos 1950, através do qual algumas áreas residenciais deterioradas no centro de Londres, ocupadas pela classe trabalhadora, estavam sendo transformadas em áreas residenciais para a classe média.

(2) Este é, de fato, o nome de uma obra coordenada por Smith e Williams (Gentrification of the city, 1986).

(3) A área conhecida como "Dona Teodora" situa-se na periferia de Porto Alegre e teve início no local conhecido como "Arraial dos Navegantes". A área abrangia, à época do início das transformações nos anos 1960, quatro bairros: Navegantes, Humaitá, Farrapos e Anchieta. Esses quatro bairros ocupam uma área de aproximadamente 840 ha. e, até a década de 1960, era ocupada predominantemente por indústrias. Para acesso a um estudo aprofundado do processo de gentrificação em "Dona Teodora”, ver Furtado (2003).

(4) Esta visão é criticada por Smith, segundo o qual, "se escolhas culturais e preferências do consumidor realmente explicam gentrificação, isto nos levaria à hipótese de que as preferências individuais mudariam em uníssono, não só nacionalmente mas também internacionalmente - uma visão desanimadora da individualidade natural e cultural humanas - ou que barreiras intransponíveis seriam fortes o suficiente para obliterar a individualidade implícita na preferência do consumidor" (1979, p. 540). 
(5) Um bom estudo sobre esta questão pode ser encontrado em Mascaró (1979).

(6) Esta decisão teve como base um estudo da UFRGS que indicava o uso industrial como a melhor vocação para a área. No entanto, nesta época as indústrias, mesmo as aí localizadas, já buscavam melhores localizações na Região Metropolitana, cedendo este espaço para o setor terciário, pois a infraestrutura existente e o custo do metro quadrado de terreno já não atendiam às necessidades do setor industrial.

\section{Referências}

ALONSO, J. A. (1988). A desindustrialização de Porto Alegre: causas e perspectivas. Ensaios FEE. Porto Alegre, v. 9, n. 1, pp. 3-28.

AYDOS, E. D. (1976). Padrões de mobilidade espacial e demanda por relocalização industrial em Porto Alegre. Porto Alegre, IESPE/PUC.

BOURDIEU, P. (1996). Razões práticas. Campinas, Papirus.

CARRION, O. B. K. (1987). Custo de consumo final da habitação: o caso da Região Metropolitana de Porto Alegre. Tese de doutorado. São Paulo, Universidade de São Paulo.

DEÁK, C. (1985). Rent theory and the price of urban land. Tese de doutorado. Cambridge, King's College/University of Cambridge.

FURTADO, C. R. (2003). Gentrificação e (re)estuturação urbana no Brasil: o caso de Porto Alegre: 19651995. Tese de doutorado. Porto Alegre, Universidade Federal do Rio Grande do Sul.

GLASS, R. (1964). London: aspects of change. Londres, MacGibbon e Kee.

HAMNETT, C. (1984). The lost gentrifiers. London. New Society. Londres, mar., pp. 415-416.

HAMNETT, C. e WILLIAMS, P. (1979). Gentrification in London-1961-1971: an empirical and theoretical analysis of social change. CURS Research Memorandum. Londres, v. 71.

HARVEY, D. (1984). The limits to capital. Oxford, Basil Blackwell.

(1985a). Consciousness and the urban experience. Oxford, Basil Blackwell.

(1985b). The urbanization of capital. Oxford, Basil Blackwell.

HAWLEY, A. e DUNCAN, O. (1957). Social area analysis. Land Economics, v. 33, pp. 340-351.

LEY, D. (1981). Inner city revitalization in Canada: Vancouver case study. Canadian Geographer, v. 25, pp. $124-248$.

MacDOWELL, L. (1982). Class, status, location and lifestyle. D202, Bloc 4, Unit 3. Milton Keynes, Open University.

MARCUSE, P. (1986). "Abandonment, gentrification and displacement: the linkages on New York city". In: SMITH, N. e WILLIAMS, P. (eds.). Gentrification of the city. Boston, Allen and Unwin. 
MARX, K. (1967). Capital. Nova York, International Publishers.

MASCARÓ, J. (1979). Custos de infra-estrutura: um ponto de partida para o desenho econômico urbano. Tese de Livre-docência em Urbanismo. São Paulo, Universidade de São Paulo.

MERRET, S. (1976). Gentrification, political economy of housing, housing and class in Britain. In: CONFERENCE OF SOCIALIST ECONOMISTS. Political Economy of Housing Workshop. Londres, pp. 44-49.

PMPA/DEMHAB (1998). Censo de núcleos e vilas irregulares de Porto Alegre - 1996-1998. Porto Alegre.

SCOTT, A. J. (1980). The urban land nexus and the state. Londres, Pion.

SMITH, N. (1979). Towards a theory of gentrification: back to the city movement by capital not people. Journal of the American Planning Association, v. 45, pp. 538-548.

(1986). "Gentrification, the frontier, and the restructuring of urban space". In: SMITH, N. e WILLIAMS, P. (orgs.). Gentrification of the city. Londres, Allen e Unwin.

SMITH, N. e WILLIAMS, P. (1986). “Alternatives to orthodoxy: invitation to a debate”. In: SMITH, N. e WILLIAMS, P. (orgs.). Gentrification of the city. Londres, Allen e Unwin.

SMOLKA, M. (1983). The production of the built environment, towards a view of the internal structuring of Brazilian cities: the Rio de Janeiro case. Proceedings of the Bartlett International Summer School. Genebra, pp. 2-4/2-10.

VILLAÇA, F. (1998). Espaço intra-urbano no Brasil. São Paulo, Studio Nobel.

Texto recebido em 9/nov/2013 Texto aprovado em 22/abr/2014 
